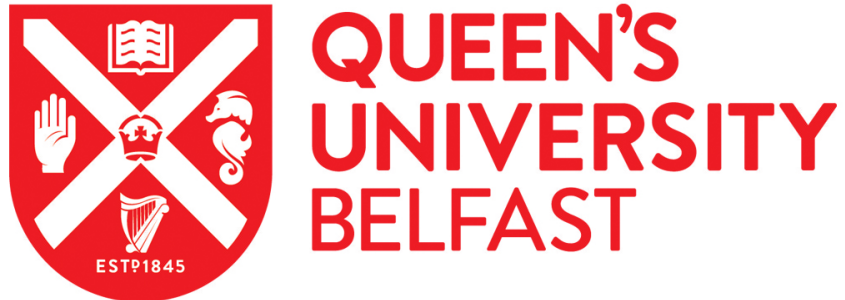

\section{Problems concerning cutting tool performance during TBM work: modelisation and testing of the rock under the action of the tool}

Innaurato, N., Oggeri, C., Oreste, P. P., \& Vinai, R. (2003). Problems concerning cutting tool performance during TBM work: modelisation and testing of the rock under the action of the tool. In J. Saveur (Ed.), Int. Cong. ITAAITES World Tunnel Congress: (Re)Claiming the Underground Space (pp. 477-482). Balkema Publishing.

Published in:

Int. Cong. ITA-AITES World Tunnel Congress

Queen's University Belfast - Research Portal:

Link to publication record in Queen's University Belfast Research Portal

\section{General rights}

Copyright for the publications made accessible via the Queen's University Belfast Research Portal is retained by the author(s) and / or other copyright owners and it is a condition of accessing these publications that users recognise and abide by the legal requirements associated with these rights.

Take down policy

The Research Portal is Queen's institutional repository that provides access to Queen's research output. Every effort has been made to ensure that content in the Research Portal does not infringe any person's rights, or applicable UK laws. If you discover content in the Research Portal that you believe breaches copyright or violates any law, please contact openaccess@qub.ac.uk. 
PROCEEDINGS OF THE ITA WORLD TUNNELLING CONGRESS 2003

12-17 APRIL 2003, AMSTERDAM, THE NETHERLANDS

\section{(Re)Claiming the Underground Space}

Edited by

J. Saveur

Scientific Committee WTC 2003, Gouda, The Netherlands

Volume 1

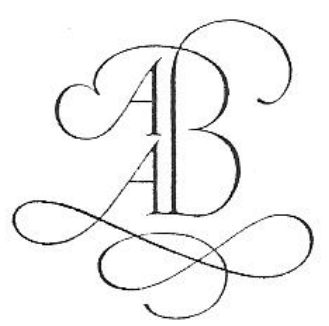

A.A. BALKEMA PUBLISHERS Lisse / ABINGDon / EXton (PA) / TOKYO 


\title{
Problems concerning cutting tool performance during TBM work: modelisation and testing of the rock under the action of the tool
}

\author{
N. Innaurato, C. Oggeri, P.P. Oreste \& R. Vinai \\ Department of Georesources and Land, Technical University of Turin Corso Duca degli Abruzzi, Turin, Italy
}

\begin{abstract}
In rock excavation engineering, cutting performance prediction plays an important role in machine and cutting tool design. In the past, experimental and theoretical studies on the interaction between rock and TBM tools were conducted for the explanation of the intimate mechanism of rock failure and to obtain knowledge that was able to improve the performances of the TBMs. Nevertheless, despite several decades of academic rock mechanics and practical rock engineering, there is still a lack of some fundamental knowledge on rock-tool interaction. The objective of this paper is to evaluate a model that predicts the distributed displacement and stresses under a TBM disk, taking into account, in the failure mode, the constitutive law of the rock, the presence of the tunnel head, the amount of the natural stress due to the high overburden, and the forces caused by the TBM disk on the tunnel head. Some laboratory tests were also planned to validate the theoretical results.
\end{abstract}

\section{INTRODUCTION}

Rock excavation and breaking is connected to various fundamental activities of the industries that work on the land: from mining to tunnelling, or to the construction of underground openings or foundations of the large infrastructures such as dams, bridges and so on. It is therefore a matter of course that this subject has captured the attention not only of technicians and specialists but also of scholars with the aim of finding the optimal way to improve the machines and tool performance. This purpose has been achieved by working on several aspects of rock machining: the knowledge of the rock-tool interaction, the consequent improvement of the tool materials, the amelioration of the rock breaking system, this being intended not only as a motor, but as an ensemble of mechanical organs linked together to produce the action of the tool.

This paper is intended to offer some new knowledge on this argument on the basis of theoretical and experimental researches, carried out over the years by the authors, especially on TBM works in tunnelling.

\section{THE MECHANICS OF ROCK DESTRUCTION}

There are different modes of inducing fragmentation or permanent deformation on the rock material by a tool. According to a hypothesis by Hartman (1959) and Maurer (1960), then summarised by other authors (i.e. Nishimatsu, 1972), and which is still able to explain such complex phenomena, rock destruction under a tool includes phases such as: rock deformation, surface crushing, formation of a destruction nucleus, squashing and spalling of the rock bounded by the destruction nucleus and the free crack surface towards a free surface. In other words, the nucleus (that may be cylindrical or spherical, Figure la) acts as a fluid subjected to a hydrostatic pressure which pushes in all directions. If a free surface is sufficiently close to the tool, the formation of chips takes place under a determined load (interactive tool). At small spacing/ penetration ( $\mathrm{s} / \mathrm{p}$ ) ratios, cracks propagating from one groove interact with the cracks produced by indentation of the cutter situated in the neighbouring groove and chip formation happens at lower forces than would be required for chip release from grooves spread further apart. At $\mathrm{s} / \mathrm{p}$ ratios that are larger than the critical value $(\mathrm{s} / \mathrm{p})_{\text {opt }}$, grooves are too far apart for the interaction to occur, and chips form at applied force levels which are independent of any further increase in the groove spacing.

The fracture propagation is however made easier by: some inter-granular defects (micro-cracks, microfissures, micro-fractures) the presence of schistosity, inter-strata planes, diaclases and fissures. The actual 


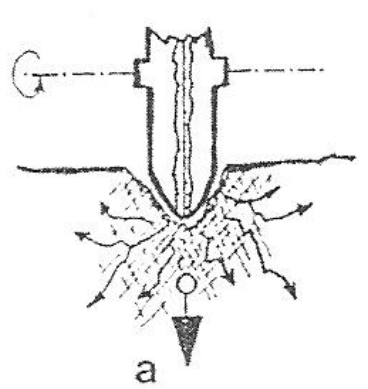

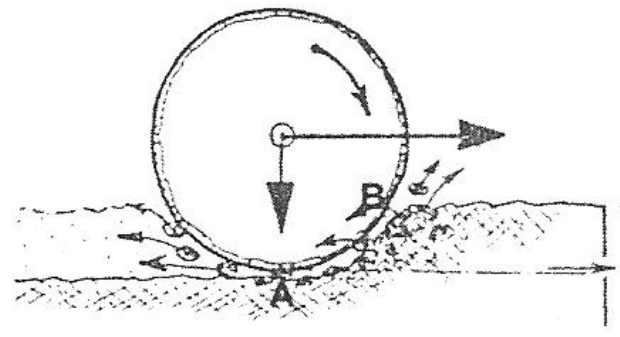

b

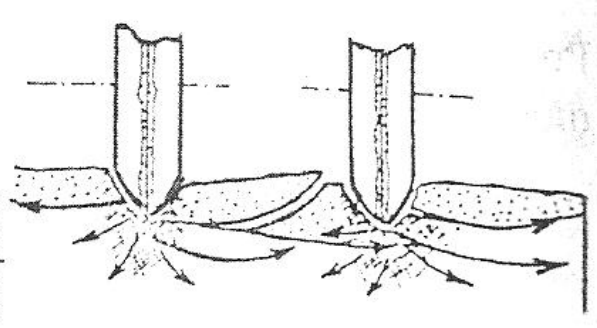

C

Figure 1. Chip formation due to TBM disk action: (a) scheme of rock destruction mechanism under a disk; (b) tangential action; (c) chip formation when the interaction between grooves exists.

start of one or other failure mechanism therefore depends on the scale of the phenomena that is involved.

The disk action on the tunnel face is initially a phenomenon at a millimetric scale, because the rock portion involved is of the same dimension as the wear tip of the disk. As long as the disk penetrates the rock, the scale of the phenomenon reaches centrimetric values (i.e. arc $\mathrm{AB}$ of Figure 1b, which from theoretical considerations can be expressed as

$$
\sqrt{2 \cdot p \cdot R}
$$

where $p$ is the penetration, $R$ the disk radius). The order of magnitude of the rock portion that is involved when the interaction of two neighbouring grooves takes place is less known. From practical considerations, this rock portion could be assigned, as an order of magnitude, according to the value of the chip length, or of the disk spacing (usually $6-8 \mathrm{~cm}$ ).

The distance under the rock tunnel head beyond which the stress produced by the tool thrust is so attenuated that it does not induce an actual effect on the fracture propagation is also not known.

The knowledge of the stress-strain state in the rock under the disk thrust (or under the cracked rock that acts as a fluid which can transmit the pressure) is much more interesting as the phenomenon is influenced by many factors.

Among these factors, mention is in particular made of the presence of high stresses on the tunnel face due to a high overburden.

There is very little evidence of the influence of tunnel confinement on the TBM disk performance and the opinions vary.

Some laboratory tests quoted in Bordet \& Comes (1975) show evidence that rock drillability under a high confinement ( $30-50 \mathrm{MPa}$ ) is reduced by up to $30 \%$. On the other hand, by the high state of confinement on the tunnel head could improve the action of the tool, establishing zones of instability on the same tunnel face.

In this paper it only the influence of a high state of confinement of the tunnel face on the action of a TBM
Table 1. Laboratory characteristics of the rocks considered in the numerical models.

\begin{tabular}{ll}
\hline UCS $(\mathrm{MPa})$ & $76^{*}-184^{* *}$ \\
TS $(\mathrm{MPa})$ & $9.2^{* * *}$ \\
Young Modulus (MPa) & 58,000 \\
Seismic velocity $(\mathrm{m} / \mathrm{s})$ & 5,500 \\
Cohesion $(\mathrm{MPa})$ & 35 \\
Friction angle $\left(^{\circ}\right)$ & 47 \\
$\mathrm{~m}_{\mathrm{i}}^{* * * *}$ & 13 \\
\hline
\end{tabular}

*UCS: Uniaxial Compression Strength (mean) on specimens of $50 \mathrm{~mm}$ diameter cored at various distance from the entrance in the Noriglio Formation;

**UCS on $30 \mathrm{~mm}$ diameter specimens cored at $385 \mathrm{~m}$ from the entrance;

***TS: Tensile Strength (Brazilian test);

*****arameter of the intact rock according to the Hock \& Brown strength criterion.

disk is taken into consideration, by means of numerical models. Indentation tests on rock specimens under confinement are also planned in the near future to check the theoretical results. Meanwhile, data derived from TBM work in a tunnel that crossed calcareous and dolomite rocks were introduced into the models.

\section{THE ROCK CHARACTERISTICS AND THE TBM PERFORMANCES CONSIDERED INTO THE NUMERICAL MODELS}

The rock characteristics that were considered for the input data for the numerical models derive from tests that were carried out on cores taken in a zone of a tunnel with the following features: length $3050 \mathrm{~m}$; diameter $3.5 \mathrm{~m}$; maximum overburden $450 \mathrm{~m}$.

The rock (called Noriglio Formation) is a grey limestone whose geo-mechanical characteristics are presented in Table 1. (Grandori et alii, 1991; Innaurato et alii, 1991).

Table 2 shows the characteristics of the TBM used in the tunnel. 
Table 2. TBM characteristics.

\begin{tabular}{ll}
\hline Diameter $(\mathrm{m})$ & 3.5 \\
Number of cutters & 27 \\
Max thrust per cutter $(\mathrm{kN})$ & 180 \\
Cutterhead power $(\mathrm{kW})$ & 520 \\
Boring stroke $(\mathrm{m})$ & 0.75 \\
\hline
\end{tabular}

Table 3. Parameters introduced into the numerical models.

\begin{tabular}{ll}
\hline Thrust per disk $(\mathrm{kN})$ & 150 \\
Penetration per round $(\mathrm{mm})$ & 6.9 \\
Disk spacing $(\mathrm{mm})$ & 65 \\
\hline
\end{tabular}

In the stretch of the tunnel considered here, (distance from the entrance $1300-1500 \mathrm{~m}$ ), the rock mass was generally of good quality, the spacing of the discontinuities was greater than $2 \mathrm{~m}$, and the discontinuity surfaces were smooth but unweathered, and sometimes damp or wet.

\section{THE DEVELOPED MODELS}

Two numerical models (FLAC Code) were developed to study the problem in detail.

The first one (model 1 ) is axisymmetrical and refers to a simulation of the tunnel excavation, in which the effect of the thrust of the disks $(150 \mathrm{kN}$ per disk) is considered by means of an equivalent pressure, acting on the tunnel face. The presence of a lining was also taken into consideration at a distance from the tunnel face of a half tunnel diameter. The calculations were carried out for the cases of 250 and $1000 \mathrm{~m}$ overburdens respectively. The following parameters were assigned to the rock mass: RMR (Rock Mass Rating) $=70$; Young modulus (derived from the RMR by the well-known formulas found in literature) $\mathrm{E}=31.6 \mathrm{GPa} ; \mathrm{UCS}=150 \mathrm{MPa}$, an intermediate value from among those shown in Table 1 . The natural state of stress was considered: $\sigma_{1}=\sigma_{3}=\gamma \cdot H$ where $\gamma=27 \mathrm{kN} / \mathrm{m}^{3}$ is the specific weight of the rock and $H=250$ and $1000 \mathrm{~m}$ are the depths of the overburdens, respectively.

The analysis with the first numerical model allowed the stress state that develops ahead of the excavation face to be obtained for the two considered depths. It proved possible to identify the entity of the confinement stresses (radial and circumferential) to which the rock is subject in the cortical zone of the face. These confinement stress values were applied to the borders of a second numerical model (model 2 in Figure 2) which allows the action of each tool to be studied more in detail. It was hypothesised that the

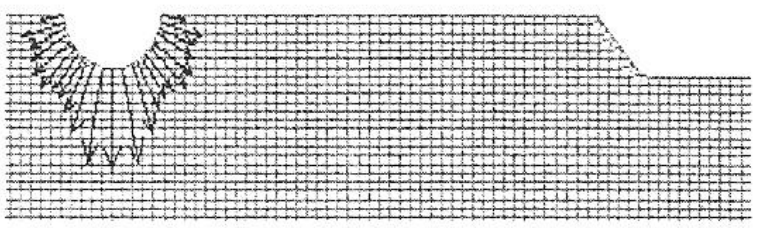

Figure 2. Simulation of the action of the tool in the just created groove, using the specifically prepared numerical model.

tool initially produces a semicircular section groove, on the walls of which the pulverised rock applies a uniform radial pressure. The effect of the radial pressure is that of inducing shear stresses and normal stresses that act on the surfaces of the potentially detachable layer of the chip.

If the geomechanical parameters of the rock are known, it is also possible to obtain the limit shear stress on the same potentially sliding surface. An elastic type behaviour of the rock was considered in the numerical calculation.

The elements that represent the rock in this second model should have very small dimensions, of the order of a millimetre. It is sufficient to consider a $1 \mathrm{~m} \times 1 \mathrm{~m}$ portion of rock below the tool.

Model 2 foresees the following calculation phases in more detail:

- attribution of deformability parameters to the elements that simulate the rock;

- application of the lateral confinement pressure to the rock block that can be considered to be influenced by the action of the tool $(1 \mathrm{~m} \times 1 \mathrm{~m}$ dimensions); the lateral pressure is the cortical stress that acts at the excavation face and which is obtained from the calculation with model 1 ;

- formation of the modelled free surface of the rock according to the results of the previous action of the contiguous tools and for the foreseen penetration;- annulment of the displacements in the model;

- gradual application of the normal pressures on the groove walls; the pressure is calculated considering that the total force applied to the tool is distributed on a depth equal to the length of the contact between the disk and the rock; this length of contact $L_{c}$ is a function of the penetration and can be expressed by the following expression:

$L_{c}=\sqrt{R^{2}-(R-p)^{2}}$

where: $R$ is the radius of the disk; $p$ is the penetration;

The applied pressure $q$ is a function of the entity of the forces acting on the tool $F$, of the diameter of 
Table 4. The geometrical characteristics of numerical model no. 2.

\begin{tabular}{ll}
\hline Number of elements & 74,760 \\
Mean length of the element & $1 \mathrm{~mm} \times 1 \mathrm{~mm}$ \\
Rock block length & $1 \mathrm{~m} \times 1 \mathrm{~m}$ \\
Penetration & $7 \mathrm{~mm}$ \\
Grove radius & $7 \mathrm{~mm}$ \\
\hline
\end{tabular}

the groove and of the length of contact $L_{c}$ :

$$
q=\frac{F}{L_{c} \cdot \phi}=\frac{F}{\sqrt{R^{2}-(R-p)^{2} \cdot \phi}}
$$

- the normal stress and the shear stress on the potential detachment surface are evaluated for each value of the applied force.

An analysis of the results of the case under examination (section 3) allowed us to show how the confinement stress state in the cortical zone ahead of the excavation face is quite homogeneous. That is, no substantial differences between the radial stresses and the circumferential stresses were registered when passing from the centre to the border of the face.

The depth of the tunnel instead remarkably influences the entity of the confinement stresses at the excavation surface. However these different confinement stress values, applied to model 2 for the detailed analysis of the behaviour of the rock below the tool, did not produce substantially different results.

As can be seen from Figure 3, the shear stresses induced on the potentially detachable surface of the chip are quite similar for the two depths of $250 \mathrm{~m}$ and $1000 \mathrm{~m}$ that were analysed. Shear stresses can be noted in both cases of about $20 \mathrm{MPa}$ below the centre of the groove, which then increase till reaching a maximum value of 60-70 MPa at a distance of about $6 \mathrm{~mm}$ ( 1.5 times the radius of the groove). They then tend to diminish sharply and remain constant at over $25 \mathrm{~mm}$ of distance from the centre of the groove produced by the tool. The normal stresses induced on the potentially detachable surface result to be very high (almost equal to $180 \mathrm{MPa}$ ) below the centre of the groove; they then decrease quickly until they disappear at a distance of $35-40 \mathrm{~mm}$ (10-11 times the radius of the groove).

At $2 \mathrm{~cm}$ from the tunnel face, the stresses result to be about $75 \mathrm{MPa}$, at $3 \mathrm{~cm}$ about $50 \mathrm{MPa}$ and at $5 \mathrm{~cm}$ about $25 \mathrm{MPa}$.

The limit shear stress obviously follows almost the same trend of the normal stress. If the Mohr-Coulomb strength criterion is considered to be valid, it is possible to obtain the trend of the limit shear stresses along the potentially detachable surface. The friction angle can be considered as being constant with a variation of scale of the problem: no great error is therefore made if the value obtained from the uniaxial and triaxial compression tests in the laboratory is used in the calculation. The uncertainties are much greater for the cohesion. This is a parameter that greatly depends on the scale of the problem. There are no reliable indications on the cohesion value at very small scales. The triaxial laboratory tests allowed us to have an estimation of the cohesion of the rock at a small scale (Table 1).

However, a back-analysis of the mechanism of detachment of the chip below the excavation head tools was carried out to have an indication of the values of cohesion at a very small scale. It was known that, with a force of 15 tons per tool in the rock under examination, detachment of the chip from the excavation surface occurred. The cohesion value was therefore varied to identify the conditions in which the shear stress acting on the potentially detachable surface would result to be higher, at least in one point, than the limit shear stress (Figure 3). As the chip breakage is of a brittle type, in the moment in which the limit conditions are reached in one point, on the potentially detachable surface, the distribution of the forces occurs immediately on the portions close by, progressively bringing the rock to break all along the potentially detachable surface.

The limit cohesion value obtained from the backanalysis results to be about $10 \mathrm{MPa}$, a value that is lower than that which was measured on the laboratory samples ( $35 \mathrm{MPa})$. Such a reduction of the cohesion can be put down to the greater influence of the microfissures of the rock mass at a very small scale. Microscopic weakness and structural defect zones, in the presence of very high concentrations of forces, make it easier for the breakage mechanism to occur along the potentially detachable surface.

In order to estimate the force per tool necessary to guarantee a certain advancement for each turn of the excavation head, it is therefore necessary to previously estimate the fictitious cohesion at a very small scale through the back-analysis of data concerning the functioning of the machine. As an alternative, special laboratory tests can be carried out that simulate the action of the excavation tool and which are able to reproduce a similar stress state in the rock close to the tool.

Numerical analysis that consider the presence of a discontinuity in the rock close to the free surface (hypothesised at $3 \mathrm{~cm}$ from the face) have allowed us to show how the breakage around the groove produced by the action of the tool is much larger than in the case in which such a discontinuity is absent. Naturally the results of the study are, in this case. purely indicative, as the uncertainties related to the nature, position and geometry of the discontinuity can greatly influence the breakage mechanism of the rock. The results indicate how the action of the tool can have a greater efficiency in the presence of natural 

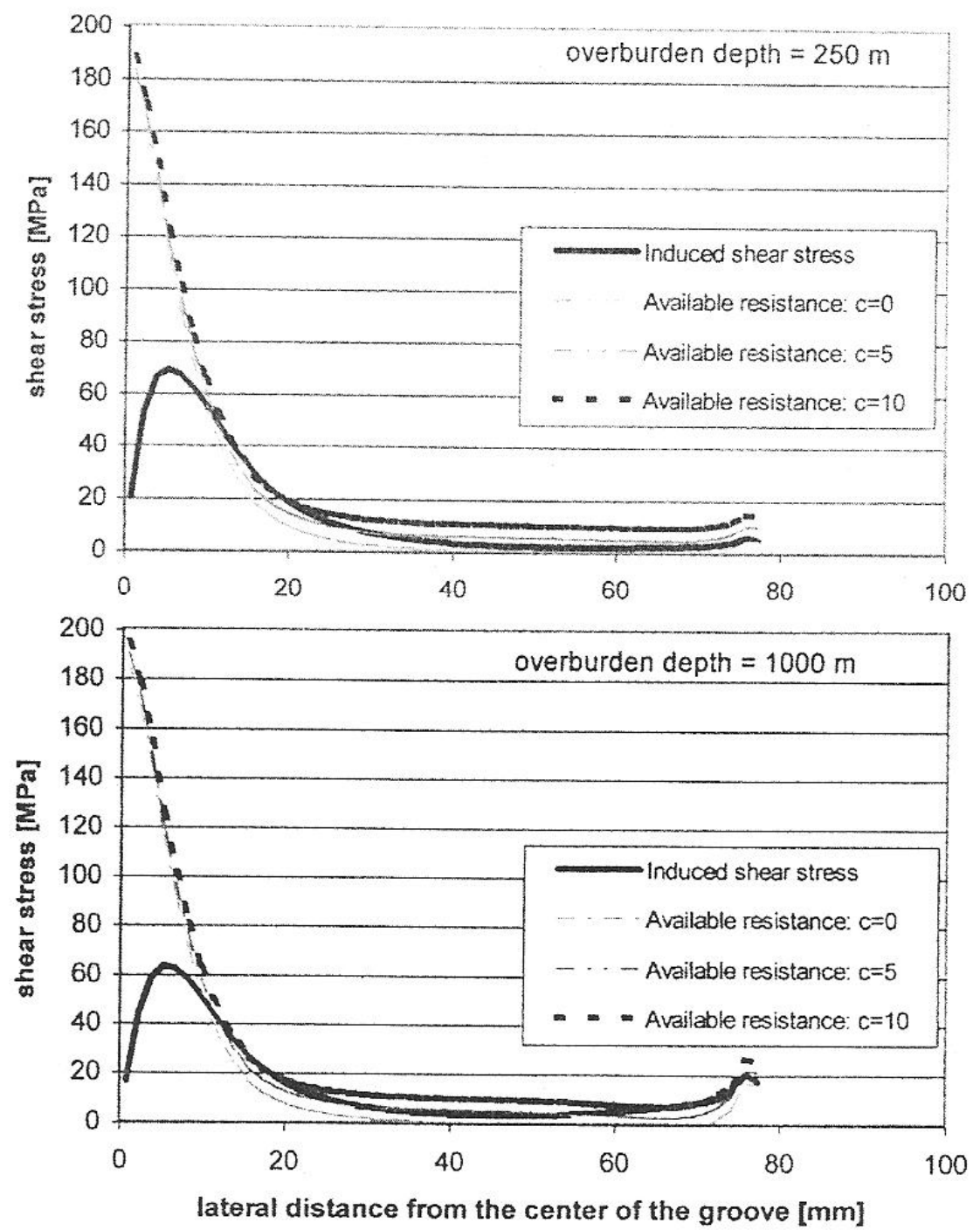

Figure 3. Trend of the acting and limit shear stress, for different values of cohesion, on the potentially detachable surface, with the distance from the axis of the groove.

discontinuities in the rock mass, confirming the experimental results found in literature.

It is necessary however to observe how an intense rock breakage at the face is not always indicative of an efficient advancement of the excavation machine as, in these cases, it can happen that the chip, breaking up, can obstruct the propagation of the forces towards the free surface or towards the groove obtained by the adjacent tool.

\section{FUTURE DEVELOPMENTS OF THE STUDY}

Based on field observed behaviour, one can consider the influence of some of the rock parameters on the chip forming process. It is possible that the microstructural pattern of the rock plays a relevant role, so do the deformability parameters and the cohesion.

For this reason the following materials should be considered and studied, both in the sense of a classical rock mechanics characterization and by means of a phenomenological observation:

- a micro-crystalline material, such as a fine marble, homogeneous;

- a micro-crystalline material, such as a fine diorite, heterogeneous;

- a macro-crystalline material, such as a limestone, homogeneous;

- an anisotropic fine material, such us a fine gneiss, heterogeneous;

- a plastic material, such as a siltstone, homogeneous. 
The first four materials could be considered as elastic - brittle materials, and therefore should be suitable for a comparison with the model results. In order to avoid other variables at this stage of the study, only the brittle rock types should be directly tested. Interesting studies were carried out in the past concerning anisotropic rock (Sanio, 1985).

The classical characterization should be carried out through the determination of the uniaxial compressive strength at different specimen diameters, tensile strengths, confined compressive strengths, and defomability parameters.

The technological characterisation should involve testing with a microhardness device and the NCB Indenter.

Finally, to perform a direct phenomenological observation (Detournay et al., 1992), some indentation tests should be performed using a cutter or a indenter tool, applying a direct force to the tool that acts on the flat surface of a large sized specimen (e.g. $15 \times 15 \mathrm{~cm})$. As the confinement lateral stress that acts at the near surface level can play a decisive role in the formation of the chip (due to the modification of the behaviour of the rock material), the specimen should be placed in a pressure box, or laterally forced, by using heavy duty jacks. A level of at least $20 \mathrm{MPa}$ should be reached to appreciate the differences in behaviour.

\section{CONCLUSIONS}

The problem of forecasting the advancement of an excavation machine and the entity of the force that is necessary for each tool to activate the mechanism of the chip formation is one of the most interesting in the field of rock engineering.

The dimensioning of the head of a TBM and the estimation of the speed of advancement of the machine are based on simple analytical calculations that try to approximate the phenomenon to some extent.

A procedure has been presented in this paper for the evaluation of the breakage of the chip along a potentially detaching surface. This procedure is based ion of a small a finite difference numerical calculaion of a small portion of rock close to the tool.
It has been possible to obtain the strength parameters (cohesion in particular) at a very small scale from the back-analysis of functioning parameters of a TBM in rock. These parameters are necessary to carefully dimension the excavation head and to foresee the advancement for each turn of the machine.

It has been noted how the fictitious cohesion of the rock at a very small scale results to be smaller than that measured in triaxial loading tests in the laboratory on normal samples.

\section{ACKNOWLEDGEMENTS}

This research has been financially supported by the Italian Ministry of the University.

\section{REFERENCES}

Bordet C. \& Comes, 1975. Etude previsionelle de la forabilité des roches au tunnellier. Tunnels et Ouvrages Souterrains 7.

Bruce N.E. \& Morrel R.J., 1970. Tunnel boring technology Disk cutter experiments in sedimentary and metamorphic rocks. In: US Bureau of Mines, R.I. N. 7410.

Cook N.G.W., Hood M. \& Tsai F, 1984. Observations of crack growth in hard rock loaded by an indenter. Int. $J$. Rock Mech. Min. Sci. \& Geomech. Abstr, 21(2): 97-107.

Detournay E. \& Defourny P., 1992. A phenomenological model for the drilling action of drag bits. Int. J. Rock Mech. Min. Sci. 29(1): 13-23.

Grandori R., Lembo-Fazio A. \& Ribacchi R., 1991. Mechanized excavation of the Rovereto hydraulic tunnel. VII Int. Congress on Rock Mechanics, Aachen, 995-1000.

Innaurato N., Mancini R., Rondena E. \& Zaninetti, A. 1991. Forecasting and effective TBM performances in a rapid excavation of a tunnel in Italy. VII lnt. Congress on Rock Mechanics. Aachen, 1009-1014.

Innaurato N., Oggeri C. \& Oreste P.P. 2001. Performance and modelling of indenters and cutting tools for the assessment of rock tunnelling borability. Proc. Eurock 2001. Espoo: 573-578, Rotterdam: Balkema ed.

Maurer W.C. \& Rinehart J.S., 1960. Impact crater formation in rock. J. Applied Physics, 31(7).

Nishimatsu Y., 1972. The mechanics of rock cutting. Int J. Rock Mech. Min. Sc. \& Geomech. Abstr. 9: 261-270.

Wickham et al. 1974. Ground support prediction model RSR concept. N.T.I.S. Re., S, Francisco. 